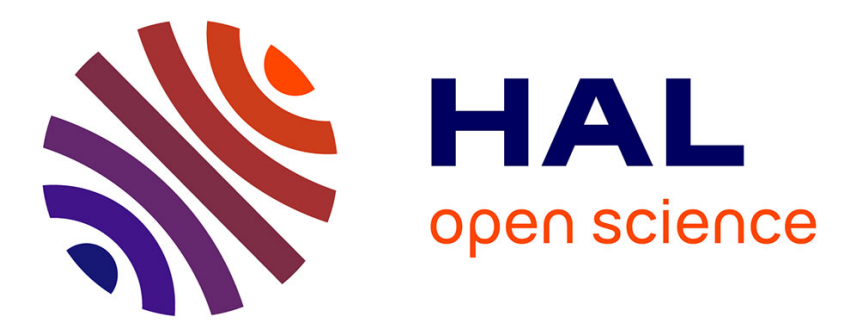

\title{
Two-level diagnostic classification using cerebrospinal fluid YKL-40 in Alzheimer's disease
}

Filippo Baldacci, Nicola Toschi, Simone Lista, Henrik Zetterberg, Kaj

Blennow, Ingo Kilimann, Stefan Teipel, Enrica Cavedo, Antonio Melo dos

Santos, Stéphane Epelbaum, et al.

\section{To cite this version:}

Filippo Baldacci, Nicola Toschi, Simone Lista, Henrik Zetterberg, Kaj Blennow, et al.. Two-level diagnostic classification using cerebrospinal fluid YKL-40 in Alzheimer's disease. Alzheimer's \& Dementia: the Journal of the Alzheimer's Association, 2017, 10.1016/j.jalz.2017.01.021 . hal-01496140

\section{HAL Id: hal-01496140 \\ https://hal.sorbonne-universite.fr/hal-01496140}

Submitted on 27 Mar 2017

HAL is a multi-disciplinary open access archive for the deposit and dissemination of scientific research documents, whether they are published or not. The documents may come from teaching and research institutions in France or abroad, or from public or private research centers.
L'archive ouverte pluridisciplinaire HAL, est destinée au dépôt et à la diffusion de documents scientifiques de niveau recherche, publiés ou non, émanant des établissements d'enseignement et de recherche français ou étrangers, des laboratoires publics ou privés. 


\section{Two-level diagnostic classification using CSF YKL-40 in Alzheimer's disease}

Filippo Baldacci ${ }^{\mathrm{a}, \mathrm{b}}$, Nicola Toschic, ${ }^{\mathrm{c}, \mathrm{d}}$, Simone Lista ${ }^{\mathrm{e}, \mathrm{f}}$, Henrik Zetterberg ${ }^{\mathrm{g}, \mathrm{h}, \mathrm{i}}$, Kaj Blennow ${ }^{\mathrm{g}, \mathrm{h}}$, Ingo Kilimann ${ }^{\mathrm{j}}$, Stefan Teipeli, Enrica Cavedo ${ }^{\mathrm{b}, \mathrm{k}}$, Antonio Melo dos Santos ${ }^{\mathrm{b}}$, Stéphane Epelbaum ${ }^{\mathrm{b}}$, Foudil Lamari $^{1}$, Bruno Dubois ${ }^{\mathrm{b}}$, Roberto Floris ${ }^{\mathrm{c}}$, Francesco Garaci ${ }^{\mathrm{c}, \mathrm{m}}$, Ubaldo Bonuccelli ${ }^{\mathrm{a}}$, and Harald Hampel ${ }^{\mathrm{b}, \mathrm{f}, *}$

${ }^{a}$ Department of Clinical and Experimental Medicine, University of Pisa, via Savi 10, Pisa, 56126, Italy

${ }^{b}$ Sorbonne Universités, Université Pierre et Marie Curie (UPMC) Paris 06, Inserm, CNRS, Institut du cerveau et de la moelle (ICM), Département de Neurologie, Institut de la Mémoire et de la Maladie d'Alzheimer (IM2A), Hôpital Pitié-Salpêtrière, Boulevard de l'hôpital, F-75013, Paris, France. ${ }^{c}$ Department of Biomedicine and Prevention, Faculty of Medicine, University of Rome "Tor Vergata”, 00173 - Roma, Italy

${ }^{d}$ Department of Radiology, Athinoula A. Martinos Center for Biomedical Imaging, Massachusetts General Hospital and Harvard Medical School, Charlestown, 02129 - Boston, MA, United States ${ }^{e} I H U-A-I C M-$ Paris Institute of Translational Neurosciences, Pitié-Salpêtrière University Hospital, 75651 - Paris, France ${ }^{f}$ AXA Research Fund \& UPMC Chair, 75005 - Paris, France

IInstitute of Neuroscience and Physiology, Departement of Psychiatry and Neurochemistry, The Sahlgrenska Academy at University of Gothenburg, S-431 80 - Mölndal, Sweden

${ }^{h}$ Clinical Neurochemistry Laboratory, Sahlgrenska University Hospital, S-431 80 - Mölndal, Sweden

${ }^{i}$ Department of Molecular Neuroscience, UCL Institute of Neurology, Queen Square, London WC1N 3BG, UK

${ }^{j}$ Department of Psychosomatic Medicine, University of Rostock, and DZNE Rostock, 18147 Rostock, Germany ${ }^{k} I R C C S$ Istituto Centro San Giovanni di Dio-Fatebenefratelli, 25125 - Brescia Italy ${ }^{l}$ AP-HP, UF Biochimie des Maladies Neuro-métaboliques, Service de Biochimie Métabolique, Groupe Hospitalier Pitié-Salpêtrière, 75651 - Paris, France

${ }^{m}$ Casa di Cura "San Raffaele Cassino", 03043 - Cassino (FR), Italy

\section{*Corresponding author:}

Harald Hampel, MD, PhD, MA, MSc

AXA Research Fund \& UPMC Chair,

Sorbonne Universities, Pierre and Marie Curie University, Paris 06,

Institute of Memory and Alzheimer's Disease (IM2A),

Brain and Spine Institute (ICM) UMR S 1127,

Department of Neurology,

Pitié-Salpêtrière University Hospital,

47 Boulevard de l'Hôpital, 75651 - Paris, CEDEX 13, France

Phone: +33157274481

Fax: +33142167516

E-mail: harald.hampel@med.uni-muenchen.de (H. Hampel)

Words count: 3819 words 


\begin{abstract}
Introduction: We assessed the diagnostic accuracy of cerebrospinal fluid (CSF) YKL-40 in discriminating: a) clinical Alzheimer's disease (AD) from cognitively healthy controls (HC), and frontotemporal dementia (FTD) (Level I), b) patients stratified by different pathophysiological profiles from $\mathrm{HC}$ and FTD following a novel unbiased/descriptive categorization based on CSF biomarkers, independently of cognitive impairment severity (Level II).
\end{abstract}

Methods: YKL-40 was compared among HC ( $n=21)$, mild cognitive impairment $(n=41), \operatorname{AD}(n=35)$, FTD ( $\mathrm{n}=9)$ (Level I); among HC ( $\mathrm{n}=21)$, subjects AD pathophysiology (tau and amyloid- $\beta$ ) negative $(n=15)$, tau-positive $(n=15)$, amyloid- $\beta$-positive $(n=13)$, AD pathophysiology-positive $(n=33)$, and FTD (n=9) (Level II).

Results: Level I: YKL-40 discriminated AD from HC and FTD (AUROCs=0.69, 0.71). Level II: YKL-40 discriminated tau-positive and AD pathophysiology-positive individuals from $\mathrm{HC}, \mathrm{AD}$ pathophysiology-positive patients from FTD (AUROCs=0.76, 0.72, 0.73).

Discussion: YKL-40 demonstrates fair performance in distinguishing tau-positive patients from HC, suggesting it may aid clinical diagnosis and support a biomarker-guided pathophysiological stratification.

Key words: Alzheimer's disease, biomarkers, biomarker-based diagnosis, cerebrospinal fluid, clinical diagnosis, dementia, diagnostic biomarkers, Frontotemporal dementia, mild cognitive impairment, neurodegeneration, neuroinflammation, YKL-40 
Abbreviations: Alzheimer's disease (AD); amyloid- $\beta 1$ to $42\left(\mathrm{~A} \beta_{1-42}\right)$; area under the receiver operating characteristic curve (AUROC); $A / T / N$ system: $A=A \beta, T=$ phospho-tau, $N=$ total-tau; cerebrospinal fluid (CSF); cognitively healthy controls (HC); ${ }^{18} \mathrm{~F}$-fluorodeoxyglucose-PET $\left({ }^{18} \mathrm{~F}\right.$ FDG-PET); False Discovery Rate (FDR); fronto-temporal dementia (FTD); hyperphosphorylated tau (p-tau); Institute of Memory and Alzheimer's Disease (IM2A); International working group-2 (IWG2); Kruskal-Wallis (KW); leave-one out cross validation (LOO-CV); mild cognitive impairment (MCI); Mental-State Examination (MMSE); National Institute on Aging-Alzheimer's Association (NIA-AA); National Institute of Neurological and Communicative Disorders and Stroke-Alzheimer's Disease and Related Disorders Association (NINCDS-ADRDA); pairwise multiple comparison of mean ranks (PMCMR); total tau (t-tau)

\section{INTRODUCTION}

Alzheimer's disease (AD) is a genetically, biologically and clinically heterogeneous multifactorial disease [1-3]. The primary pathological hallmarks are amyloid plaques consisting of aggregated amyloid- $\beta$ and neurofibrillary tangles containing hyperphosphorylated and aggregated tau protein [3]. However, in most of patients, AD related brain changes are combined with other types of pathologies [4,5]. Currently, three core, feasible cerebrospinal fluid (CSF) biomarkers have shown to track pathophysiological mechanisms in vivo in preclinical, prodromal and $\mathrm{AD}$ dementia [6,7]. In particular, (I) CSF concentrations of the amyloid- $\beta 1$ to $42\left(\mathrm{~A} \beta_{1-42}\right)$ peptide is considered a biomarker of brain amyloid deposition, (II) total tau (t-tau) protein is considered a marker of neuronal injury in several brain diseases (not pathognomonic for AD) and (III) hyperphosphorylated tau ( $\mathrm{p}$-tau) protein is considered a marker reflecting hyperphosphorylation of tau leading to the formation of paired helical filaments and ultimately neurofibrillary tangles [8]. Although neuroinflammation has been consistently suggested with accumulating evidence to contribute as additional pathophysiological mechanism to AD [1,9], a clinically validated and standardized CSF inflammation biomarker for both diagnosis and as indicator of mechanism of action in trials has not yet been developed.

In particular, YKL-40, a glycoprotein belonging to the chitinase-like proteins group, represents a promising candidate inflammation biomarker in progressive clinical development for AD. However, its pathophysiological functions are not yet fully clarified [10]. YKL-40 is a differentiation marker of 
macrophages [11-13] and is expressed in microglia and astroglia within the central nervous system [14].

Recently, in first clinical investigations, statistically significant elevated CSF concentrations of YKL-40 were reported in AD compared with cognitively healthy controls (HC), in agreement with reported increased concentrations at the prodromal and preclinical stages [15-28].

The main objective of this study was to assess the diagnostic accuracy of CSF YKL-40 in diagnosing and categorizing individuals with cognitive impairment.

In a first step (Level I), we tested the performance of YKL-40 in discriminating clinically diagnosed patients with $\mathrm{AD}$ dementia from $\mathrm{HC}$ subjects and patients with frontotemporal dementia (FTD).

In a second step of analysis (Level II) [4], we evaluated the classificatory performance of YKL40 across the spectrum of AD pathology by adopting a recently published unbiased descriptive categorization system based on biomarker-guidance only, namely the " $\mathrm{A} / \mathrm{T} / \mathrm{N}$ " scheme, using $\mathrm{AD}$ core biomarkers. The $\mathrm{A} / \mathrm{T} / \mathrm{N}$ system comprises three binary components, $\mathrm{A}=\mathrm{A} \beta$ pathology, $\mathrm{T}=$ tau pathology, $\mathrm{N}=$ neurodegeneration for characterizing features of $\mathrm{AD}$ pathology/pathophysiology (independently from the severity of cognitive impairment). To this end, we determined the discriminatory performance of CSF YKL-40 in distinguishing HC from I) AD pathology patients (presenting both decreased CSF concentrations of $A \beta_{1-42}$ peptide and increased t-tau or $p$-tau protein [7]), II) patients showing tau pathology only, and III) patients with A $\beta$ pathology only. In addition, we explored the ability of CSF YKL-40 to discriminate AD pathology patients from FTD cases.

\section{METHODS}

\subsection{Population}

A total of 135 individuals from a convenience sample were examined. Of these participants, 27 were excluded due to missing data in one or more CSF biomarkers and the remaining 108 were included in the present study. Clinical and biological data from these 108 individuals $(\mathrm{AD}=35, \mathrm{FTD}=$ 
9, $\mathrm{MCI}=41$, and cognitively $\mathrm{HC}=23$ ) were retrospectively collected in a multi-centre cross-sectional study involving three independent academic AD research centres and expert memory clinics. Thirtyfive subjects were recruited at the Institute of Memory and Alzheimer's Disease (IM2A) at PitiéSalpêtrière University Hospital in Paris (France); 57 at the German Centre for Neurodegenerative Diseases (DZNE) in Rostock (Germany); 16 at the Institute of Neuroscience and Physiology at Sahlgrenska University Hospital in Göteborg (Sweden).

The study was conducted according to the provisions of the Declaration of Helsinki. All participants or their representatives gave written informed consent for the use of their clinical data for research purposes and the local Ethical Committees at the respective universities approved the study. We followed the STARD criteria for the reporting of diagnostic test accuracy studies (available at http://www.equator-network.org/reporting-guidelines/stard/).

\subsection{Patient stratification}

\subsubsection{Level I (purely clinical diagnostic approach)}

The first group was composed of 23 cognitively HC. Two individuals from the Göteborg cohort were identified as asymptomatic-at-risk of $\mathrm{AD}$ [7] or preclinical $\mathrm{AD}$ [29] showing high CSF t-tau concentrations. While tau positivity is a criterion which pertains purely to level II, we decided to exclude two asymptomatic subjects showing positivity to CSF t-tau from the HC group in order to perform both level I and level II analyses on identical populations. The second group included 41 subjects with MCI [6]. The third group included 35 patients with AD dementia [30]. Finally, the fourth group included 9 patients with FTD [31] (Figure 1). The clinical diagnosis of AD dementia was performed according to the National Institute of Neurological and Communicative Disorders and Stroke-Alzheimer's Disease and Related Disorders Association (NINCDS-ADRDA) consensus criteria [30]. The clinical diagnosis of MCI was made according to the MCI core clinical criteria [6]. The clinical diagnosis of FTD was made following the consensus on clinical diagnostic criteria of 1998 [31]. Cognitively HC were individuals who volunteered for lumbar puncture; the inclusion 
criteria comprised absence of history of neurological or psychiatric diseases and Mental-State Examination (MMSE) scores between 27 and 30.

\subsubsection{Level II (unbiased categorization based on CSF core biomarker profiles)}

The categorization of $\mathrm{AD}$ dementia patients and individuals with MCI followed the unbiased biomarker-based descriptive classification system recently proposed by Jack and colleagues: the "A/T/N" system [4]. This classification considers 3 binary (i.e. positive or negative) categories: "A" referring to an amyloid biomarker (CSF $\mathrm{A} \beta_{1-42}$ or amyloid-PET), " $\mathrm{T}$ " to a tau pathology biomarker (CSF p-tau or tau-PET), and "N" to a quantitative or topographic biomarker of neurodegeneration or neuronal injury (CSF t-tau, ${ }^{18}$ F-fluorodeoxyglucose-PET $\left({ }^{18}\right.$ F-FDG-PET), or structural MRI). Since each individual score is displayed as an " $\mathrm{A} \pm / \mathrm{T} \pm / \mathrm{N} \pm$ " arrangement, eight different categories are possible [4]. The A/T/N classification system is linked to the biomarker classification frameworks of the International working group-2 (IWG-2) criteria [7] and the National Institute on AgingAlzheimer's Association (NIA-AA) guidelines [4,29,32], and is able to chart both diagnostic classifications. For practical reasons the A/T/N system was utilized in a simplified version which employed only CSF markers and excluded imaging-methods (amyloid PET, tau PET, FDG-PET, or structural MRI) to define 5 categories (groups) which were independent from severity of cognitive impairment:

Group 1 consisted of cognitively HC $(n=21)$, a priori defined as both $\mathrm{A} \beta$ and tau negative [A-/T/N-]; group 2 [A-/T-/N-] $(\mathrm{n}=15)$ included $2 \mathrm{AD}$ dementia patients and 13 MCI subjects which were both $\mathrm{A} \beta$ and tau negative; group $3[\mathrm{~A}-/ \mathrm{T} \pm / \mathrm{N}+$ or $\mathrm{A}-/ \mathrm{T}+/ \mathrm{N} \pm](\mathrm{n}=15)$ encompassed $6 \mathrm{AD}$ dementia patients and 9 MCI subjects which were tau positive but $A \beta$ negative; group $4[\mathrm{~A}+/ \mathrm{T}-\mathrm{N}-](\mathrm{n}=13)$ comprised $5 \mathrm{AD}$ dementia patients and $8 \mathrm{MCI}$ subjects which were $\mathrm{A} \beta$ positive only; group 5 $[\mathrm{A}+/ \mathrm{T} \pm / \mathrm{N}+$ or $\mathrm{A}+/ \mathrm{T}+/ \mathrm{N} \pm](\mathrm{n}=33)$ included $22 \mathrm{AD}$ dementia patients in line with the IWG-2 criteria [7] and the NIA-AA guidelines [32], and 11 prodromal AD [33] or MCI due to AD [6] cases, all of which were both $A \beta$ and tau positive; group 6 comprised all FTD patients $(n=9)$ including seven 
participants which were both $A \beta_{1-42}$ and tau negative, one which was $A \beta_{1-42}$ negative and tau positive, and one which was $A \beta_{1-42}$ positive and tau negative. According to the IWG-2 criteria, this last participant should be defined as a case of FTD and not as a patient with a frontal variant of AD [7]. Of note, since the $\mathrm{A} / \mathrm{T} / \mathrm{N}$ system is not directly applicable to FTD, this last group was analysed exclusively in terms of clinical diagnosis (Figure 1).

\subsection{CSF sampling}

All CSF samples were collected in polypropylene tubes, centrifuged $\left(1000 \mathrm{~g}, 10\right.$ minutes, $+4^{\circ} \mathrm{C}$ (sample collected at IM2A laboratory for the Paris cohort), $1500 \mathrm{~g}, 10$ minutes, $+4^{\circ} \mathrm{C}$ (sample collected at DZNE laboratory for the Rostock cohort), $1800 \mathrm{~g}, 10$ minutes, $+4^{\circ} \mathrm{C}$ (sample collected at Mölndal Clinical Neurochemistry Laboratory for the Göteborg cohort)), and the collected supernatant was stored at $-80^{\circ} \mathrm{C}$ pending biochemical analysis.

\subsection{Immunoassays for core biomarkers}

The core AD CSF biomarkers (A $\beta_{1-42}$, t-tau, and $\mathrm{p}$-tau) were measured in each subject. For the Paris cohort, CSF analyses were performed at the Laboratory of Biochemistry, Unit of Biochemistry of Neurometabolic diseases, Pitié-Salpêtrière University Hospital of Paris.

For the Rostock cohort, CSF analyses were executed in two different units: the Institute of Clinical Chemistry and Laboratory Medicine, Rostock University Medical Centre, after 06/2012, and the Laboratory of Neurochemistry, Department of Neurology, Göttingen University Medical Centre, before $06 / 2012$.

For the Gothenburg cohort, CSF analyses were executed at the Clinical Neurochemistry Laboratory at the Sahlgrenska University Hospital, Mölndal.

T-tau was measured using a sandwich ELISA (INNOTEST hTAU-Ag, Fujirebio Europe, Gent, Belgium) specifically constructed to measure all tau isoforms irrespective of phosphorylation status [34]. Tau phosphorylated at threonine $181\left(\mathrm{P}-\operatorname{tau}_{181}\right)$ was measured using a sandwich ELISA 
(INNOTEST Phospho-Tau[181P], Fujirebio Europe, Gent, Belgium) constructed to specifically measure tau protein phosphorylated at the amino acid threonine 181 [35]. $A \beta_{1-42}$ was measured using a sandwich ELISA (INNOTEST $\beta$-AMYLOID(1-42), Fujirebio Europe, Gent, Belgium), specifically constructed for the quantitative determination of $A \beta_{1-42}$ [36]. All analysis were performed by boardcertified laboratory technicians blinded to clinical information.

CSF biomarkers abnormalities were defined based on reference threshold cut-off values currently used in each memory clinic: at IM2A in Paris, $A \beta_{1-42}<500 \mathrm{pg} / \mathrm{mL}, \mathrm{t}$-tau $>450 \mathrm{pg} / \mathrm{mL}, \mathrm{p}$-tau $181>60$ $\mathrm{pg} / \mathrm{mL}$; at DZNE in Rostock, $\mathrm{A} \beta_{1-42}<567 \mathrm{pg} / \mathrm{mL}, \mathrm{t}-\mathrm{tau}>512 \mathrm{pg} / \mathrm{mL}, \mathrm{p}$-tau $181>66 \mathrm{pg} / \mathrm{mL}$ for the CSF samples measured before $06 / 2012$ and $A \beta_{1-42}<450 \mathrm{pg} / \mathrm{mL}, \mathrm{t}$-tau $>450 \mathrm{pg} / \mathrm{mL}, \mathrm{p}$-tau $181>62 \mathrm{pg} / \mathrm{mL}$ for the CSF sampels measured after 06/2012; at Mölndal Clinical Neurochemistry Laboratory, A $\beta_{1-42<}$ $550 \mathrm{pg} / \mathrm{mL}, \mathrm{t}-\mathrm{tau}>400 \mathrm{pg} / \mathrm{mL}, \mathrm{p}-\mathrm{tau}_{181}>80 \mathrm{pg} / \mathrm{mL}$.

\subsection{Immunoassay for YKL-40}

All CSF YKL-40 analyses were performed at the Clinical Neurochemistry Laboratory at the Sahlgrenska University Hospital, Mölndal, Sweden, using a commercial available ELISA kit (R\&D Systems, Minneapolis, MN, US), according to manufacturer instructions. The measurements were performed in one round of experiments using one batch of reagents by board-certified laboratory technicians who were blinded to clinical data. Intra-assay coefficients of variation were below $10 \%$. All samples were well within the linear range of the assay.

\subsection{Statistical Analysis}

Associations between sex and diagnostic group were assessed by Fisher's exact test, and the associations between age and diagnostic group was assessed through a nonparametric Kruskal-Wallis (KW) test. Subsequently, as a preprocessing step, all YKL-40 values were adjusted for age, sex and site employing nonparametric regression to enable age-, sex- and site- independent assessment of the diagnostic potential of YKL-40 while foregoing assumptions of normality. Correlations of YKL-40 
with core biomarkers in the entire sample were executed using Spearman's rank-order correlation test. Hence, we conducted group-wise comparisons of YKL-40 values through nonparametric KW tests followed by pairwise post-hoc comparison (Conover's-test for multiple comparisons) whenever the result of the KW test was statistically significant $(p<0.05)$. Results of post-hoc testing were corrected for multiple comparisons using a False Discovery Rate (FDR) procedure $(\alpha=0.05)$.

We then evaluated the diagnostic potential of YKL-40 using logistic regression within a leave-one out cross validation (LOO-CV) approach in the following a priori comparisons: $\mathrm{HC}$ vs. $\mathrm{AD}$ and $\mathrm{AD}$ vs. FTD (Level I), HC vs. group $3[\mathrm{~A}-/ \mathrm{T} \pm / \mathrm{N}+$ or $\mathrm{A}-/ \mathrm{T}+/ \mathrm{N} \pm], \mathrm{HC}$ vs. group $4[\mathrm{~A}+/ \mathrm{T}-/ \mathrm{N}-]$, $\mathrm{HC}$ vs. group $5[\mathrm{~A}+/ \mathrm{T} \pm / \mathrm{N}+$ or $\mathrm{A}+/ \mathrm{T}+/ \mathrm{N} \pm]$ (Level II). In this analysis, the age-, sex-, and site adjusted YKL40 values were entered as predictors and the diagnostic group was entered as the dependent variable. After model fitting, we calculated the area under the receiver operating characteristic curve (AUROC) and its associated confidence intervals using a bootstrap procedure (100000 bootstraps) [37] by pooling predictions computed on the test sets from each train-test split in the LOO-CV procedure. The discriminatory ability of YKL-40 to correctly allocate participants to diagnostic groups was classified as follows: excellent (AUROC 0.90-1.00), good (AUROC 0.80-0.89), fair (AUROC 0.700.79), poor (AUROC 0.60-0.69), or fail/no discriminatory capacity (AUROC 0.50-0.59) [38].

All statistical analyses were performed in the R statistical environment version 3.2.3 (available at https://www.R-project.org/) under a Linux environment using the nonparametric kernel smoothing methods for mixed data types package (np package) [39], partial ROC (pROC) package [37], and the pairwise multiple comparison of mean ranks (PMCMR) package [40]. Two-tailed $\mathrm{P}$ values $<0.05$ were considered statistically significant.

\section{RESULTS}

\subsection{Correlations of CSF YKL-40 with core biomarkers in the entire sample}


YKL-40 significantly correlated with $\mathrm{p}$-tau $(\rho \mathrm{s}=0.574, P<0.001)$ and $\mathrm{t}$-tau $(\rho \mathrm{s}=0.554, P<0.001)$ but not with $\mathrm{A} \beta(\rho \mathrm{s}=0.002, P=0.980)$ in the entire population after adjusting for age, sex and site (Supplementary materials).

\subsection{CSF YKL-40 concentrations in the population categorized according to Level I}

Table 1 summarizes the concentrations of all analytes, combined with the demographic and clinical data of the population classified in line with Level I classification. Cognitively HC were slightly but significantly younger than MCI, AD, and FTD patients. MMSE scores were significantly lower in AD compared with cognitively $\mathrm{HC}$ and MCI. Compared with the HC group, CSF YKL-40 concentrations were significantly increased in $\mathrm{AD}(P=0.032)$ and FTD patients $(P=0.049)$ (Figure 2A).

\subsection{CSF YKL-40 concentrations in the population categorized according to Level II}

Table 2 summarizes the concentrations of all analytes, combined with the demographic and clinical data of the population classified in line with Level II criteria. Cognitively HC (group 1) and patients belonging to group 2 [A-T-N-] were significantly younger than all the other groups (Table 1). Compared with group 1 (HC), CSF YKL-40 concentrations were significantly increased in group $3[\mathrm{~A}-/ \mathrm{T} \pm / \mathrm{N}+$ or $\mathrm{A}-/ \mathrm{T}+/ \mathrm{N} \pm](P=0.002)$ and group $5[\mathrm{~A}+/ \mathrm{T} \pm / \mathrm{N}+$ or $\mathrm{A}+/ \mathrm{T}+/ \mathrm{N} \pm](P=0.002)$. Group 3 $[\mathrm{A}-/ \mathrm{T} \pm / \mathrm{N}+$ or $\mathrm{A}-/ \mathrm{T}+/ \mathrm{N} \pm]$ and group $5[\mathrm{~A}+/ \mathrm{T} \pm / \mathrm{N}+$ or $\mathrm{A}+/ \mathrm{T}+/ \mathrm{N} \pm]$ patients presented substantially higher CSF YKL-40 concentrations compared with group 4 [A+/T-/N-] $(P<0.001$ for both $)$ patients as well as compared with those belonging to the FTD group ( $P=0.006$ and $P=0.007$, respectively); group $3[\mathrm{~A}-/ \mathrm{T} \pm / \mathrm{N}+$ or $\mathrm{A}-/ \mathrm{T}+/ \mathrm{N} \pm]$ patients presented higher $\mathrm{CSF}$ YKL-40 concentrations compared with group 2 [A-/T-/N-] patients $(P=0.033)$, (Figure 2B).

\subsection{Diagnostic value of CSF YKL-40 in the population at Level I}


CSF YKL-40 differentiated HC from AD patients with an AUROC of 0.69 (95\% CI, 0.55-0.84)

(Figure 3A). CSF YKL-40 discriminated AD from FTD patients with an AUROC of $0.71(95 \% \mathrm{CI}$, 0.51-0.91) (Figure 3B) .

\subsection{Discriminative value of CSF YKL-40 in the population at Level II}

CSF YKL-40 discriminated cognitively $\mathrm{HC}$ from group 3 [A-/ \pm $\pm / \mathrm{N}+$ or $\mathrm{A}-/ \mathrm{T}+/ \mathrm{N} \pm]$, group $4[\mathrm{~A}-$ $/ \mathrm{T} \pm / \mathrm{N}+$ or $\mathrm{A}-/ \mathrm{T}+/ \mathrm{N} \pm]$, group $5[\mathrm{~A}+/ \mathrm{T} \pm / \mathrm{N}+$ or $\mathrm{A}+/ \mathrm{T}+/ \mathrm{N} \pm]$ with $\mathrm{AUROCs}=0.76,(95 \% \mathrm{CI}, 0.58-0.94)$ 0.52 (95\% CI, 0.29-0.74), and 0.72 (95\% CI, 0.58-0.87) (Figure 4A-C), respectively. CSF YKL-40 differentiated group $5[\mathrm{~A}+/ \mathrm{T} \pm / \mathrm{N}+$ or $\mathrm{A}+/ \mathrm{T}+/ \mathrm{N} \pm]$ from FTD patients with $\mathrm{AUROC}=0.73(95 \% \mathrm{CI}$, 0.54-0.92) (Figure 4D).

\section{DISCUSSION}

In the applied diagnostic Level I approach, using clinical diagnostic criteria, CSF YKL-40 concentrations were significantly increased in clinically diagnosed AD patients compared with HC (Figure 2A). Moreover, the corresponding AUROC was poor/borderline fair in discriminating the two groups (Figure 3A). These findings partly confirm previous diagnostic studies $[16,18,20,25,26,28]$ and data from a recent meta-analysis [14]; in contrast, one study showed no differences between AD and HC [22]. Importantly, AD patients showed higher concentrations of CSF YKL-40 compared with FTD; indeed, CSF YKL-40 exhibits a fair performance in distinguishing between the two groups (Figure 3B). In the literature, very few studies evaluated the diagnostic accuracy of CSF YKL-40 in discriminating between AD and FTD patients, and reported conflicting results. In particular, Craig-Shapiro and colleagues documented higher concentrations of CSF YKL40 in FTD compared with mild AD [18]; conversely, two other studies found no significant differences between AD and FTD [15,19].

In the applied Level II approach, CSF YKL-40 concentrations were shown to be significantly increased in patients who were tau-positive only and in those with AD pathophysiology versus HC 
(group 1) (Figure 2B). We found that YKL-40 exhibited a fair performance in discriminating taupositive and $\mathrm{AD}$ pathophysiology-positive patients from $\mathrm{HC}$ (Figure $\mathbf{4 A}$ and $4 \mathrm{C}$ ), but not in discriminating $\mathrm{A} \beta$-positive only patients from $\mathrm{HC}$ (Figure 4B). These results are generally in agreement with studies indicating that CSF YKL-40 is more associated to tau protein pathology than to $A \beta$ pathology $[15,17,19,20,23,24]$; this is confirmed in our results in terms of a positive correlation of YKL-40 with p-tau and t-tau. Tau-positive patients revealed higher CSF concentrations of YKL40 compared with patients $\mathrm{AD}$ pathophysiology-negative, patients $\mathrm{A} \beta$-positive only, and FTD patients. Similarly, AD pathophysiology-positive patients showed higher CSF concentrations of YKL-40 compared with patients A $\beta$-positive only, FTD patients, and a trend towards higher concentrations of YKL-40 versus AD pathophysiology-negative patients. In particular, the AUROC related to the discrimination between AD pathophysiology and FTD patients was fair (Figure 4D), i.e. equivalent to what we found in Level I analysis. Several explanations support the fact that FTD patients can display lower concentrations of CSF YKL-40 compared with those detected in AD patients. In particular, FTD patients may have underlying mechanisms related to neurodegeneration, not associated with tau protein [41]. This mechanistic pathophysiological variability possibly reflects the common finding that clinically diagnosed FTD is a heterogeneous biological and clinical syndrome with different and overlapping phenotypes and endophenotypes. Further studies conducted in large samples of demented patients are needed to systematically assess how CSF YKL-40 could differentiate $\mathrm{AD}$ from other neurodegenerative dementias including not only FTD but also dementia with Lewy body, Parkinson's disease dementia, atypical parkinsonisms, and, additionally, vascular dementia.

CSF YKL-40 can be considered as a biomarker of a specific pathophysiological mechanism, allowing for in vivo measurement of neuroinflammation that may be complementary to the core, feasible CSF AD biomarkers $A \beta_{1-42}$, t-tau, and $p$-tau. The importance of having a dynamic early biomarker of neuroinflammation in $\mathrm{AD}$ is intriguing not only for diagnostic purposes (given that neuroinflammation is probably involved in a number of other neurodegenerative diseases [42]) but 
also because it can be predictive as an outcome of response to novel anti-inflammatory drugs. In fact, epidemiological studies indicate that non-steroidal anti-inflammatory drugs (NSAIDs) may lower the risk of $\mathrm{AD}[43,44]$, although a number of trials reported negative results [9]. However, antiinflammatory treatments may not be efficacious when administered during the dementia stage of AD. Notably, the naproxen trial in AD initially reported negative results; conversely, longer-term followup results suggested that naproxen may exert a protective role in asymptomatic subjects at baseline, thus reducing the conversion rate to $\mathrm{AD}[45,46]$. Therefore, the discovery and validation of a reliable inflammation biomarker in prodromal $\mathrm{AD}$ as well as in the preclinical stage, aiming at tracking the response to an anti-inflammatory drug in the respective target population, may be supportive for developing novel therapeutic strategies for AD.

To our knowledge, in our study we apply YKL-40 for the first time as a diagnostic CSF biomarker for $\mathrm{AD}$ founded on the unbiased biomarker-based classification scheme [4].

Some limitations of our study need to be mentioned. First, in Level II, the categorization of our patients was only based on CSF biomarkers, i.e. the $\mathrm{A} / \mathrm{T} / \mathrm{N}$ system was used without considering additional information derived from neuroimaging methods. Moreover, this dataset allows for a crosssectional study and longitudinal data are not yet available. In particular, we cannot differentiate potentially stable MCI subjects from those progressing and converting to dementia, or to provide data about a potential differing prognosis and rate of disease progression. Furthermore, the diagnosis of MCI was made in a routine clinical setting and additional extensive and/or homogeneous psychometric data were not available. Moreover, given the limited number of patients, and possible resulting lack of power, we were not able to test CSF YKL-40 concentrations in all possible (eight) categories originally reported by Jack and colleagues [4]; a comprehensive investigation of all these categories would have significantly higher numerosities. In this regard, further studies are also needed to determine the prevalence, currently largely unknown, of some of the A/T/N system categories (e.g. A-/T+/N- category) whithin the MCI and clinical AD populations. Nonetheless, in this respect, we adopted the following rationale in merging some of the $\mathrm{A} / \mathrm{T} / \mathrm{N}$ subcategories: groups of subjects with 
both decreased CSF levels of $A \beta$ and increased t-tau, or decreased CSF A $\beta$ and increased p-tau, or decreased CSF A $\beta$ and increased p-tau and t-tau were merged in one group since they show all the pathophysiological features necessary for $\mathrm{AD}$ diagnosis [7,32]. On the other hand, the positivity to only CSF A $\beta$, or only t-tau, or only p-tau, or both $p$-tau and t-tau but not A $\beta$ is presently not accepted for $\mathrm{AD}$ diagnosis [7,32]; therefore, these four groups disclosing uncomplete $\mathrm{AD}$ pathophysiological features were merged in 2 largest groups (A $\beta$-positive only and tau-positive only groups, respectively).

Furthermore, we merged MCI subjects with $\mathrm{AD}$ dementia patients on the basis of core biomarkers characterization, without considering the degree of severity of cognitive impairment. Actually, the clinical distinction between MCI and dementia is not very precise and time dependent; in this regard, the IWG-2 criteria consider MCI subjects with AD pathophysiology as AD in its prodromal phase [7]. Finally, with the exception of YKL-40, the measurements of the core CSF AD biomarkers were performed in different academic expert laboratories and, while we controlled for center effects in our statistical analysis by integrating CSF biomarkers values adjusted for site, additional inter-laboratory variability cannot be completely ruled out.

In conclusion, our results indicate that CSF YKL-40 diagnostic performance is poor to borderline fair. Therefore, CSF YKL-40 analysis does not satisfactorily support the diagnosis of AD dementia patients from cognitively HC based on clinical categorization. CSF YKL-40, however, delivers a fair performance in discriminating between clinical AD dementia and FTD patients. Based on unbiased core biomarker classification, CSF YKL-40 concentrations fairly distinguishes HC individuals from cognitively impaired patients with both $A \beta$ and tau pathology and cognitively impaired patients with tau pathology only, and patients with both $\mathrm{A} \beta$ and tau pathology from FTD patients. In contrast, CSF YKL-40 concentrations were not useful in distinguishing between HC and cognitively impaired patients who were A $\beta$-positive only. Overall, CSF YKL-40 does not sufficiently support the differentiation between $\mathrm{AD}$ dementia patients and patients with $\mathrm{AD}$ pathophysiology from $\mathrm{HC}$ subjects or patients with FTD. However, our results confirm that CSF YKL-40 can be considered as 
a candidate biomarker of neuroinflammation potentially related to neurodegenerative processes associated with increased tau protein, thus suggesting a supportive role in clinical diagnosis and patient stratification.

In perspective, large longitudinal studies, possibly enriched with confirmatory post-mortem data, one may investigate the $\mathrm{AD}$ pathophysiological spectrum by applying the unbiased $\mathrm{A} / \mathrm{T} / \mathrm{N}$ classification system which can be considered an adaptive and flexible "open source" approach, based on a pattern of established biomarkers which, however, can be potentially expanded to integrate novel emerging validated biological markers, genetic and epigenetic factors [47] as well as indicators connecting different systems dimensions of pathology and pathophysiology, such as MRI-derived grey matter atrophy or functionally relevant burden of white matter damage [48]. Moreover, there is sufficient evidence in the literature of a number of other potentially complementary promising candidate biomarkers of inflammation that deserve further development, validation and standardization, such as the interleukin- 6 and 12 , tumor necrosis factor alpha receptor components as well as components of the complement system pathways in $\mathrm{AD}[1,49]$.

\section{REFERENCES}

[1] Heppner FL, Ransohoff RM, Becher B. Immune attack: the role of inflammation in Alzheimer disease. Nat Rev Neurosci 2015;16:358-72. doi:10.1038/nrn3880.

[2] Zlokovic BV. Neurovascular pathways to neurodegeneration in Alzheimer's disease and other disorders. Nat Rev Neurosci 2011;12:723-38. doi:10.1038/nrn3114.

[3] Blennow K, de Leon MJ, Zetterberg H. Alzheimer's disease. Lancet Lond Engl 2006;368:387-403. doi:10.1016/S0140-6736(06)69113-7.

[4] Jack CR, Bennett DA, Blennow K, Carrillo MC, Feldman HH, Frisoni GB, et al. A/T/N: An unbiased descriptive classification scheme for Alzheimer disease biomarkers. Neurology 2016;87(5):539-47. doi:10.1212/WNL.0000000000002923.

[5] Kovacs GG, Milenkovic I, Wöhrer A, Höftberger R, Gelpi E, Haberler C, et al. NonAlzheimer neurodegenerative pathologies and their combinations are more frequent than commonly believed in the elderly brain: a community-based autopsy series. Acta Neuropathol (Berl) 2013;126:365-84. doi:10.1007/s00401-013-1157-y.

[6] Albert MS, DeKosky ST, Dickson D, Dubois B, Feldman HH, Fox NC, et al. The diagnosis of mild cognitive impairment due to Alzheimer's disease: recommendations from the National Institute on Aging-Alzheimer's Association workgroups on diagnostic guidelines for 
Alzheimer's disease. Alzheimers Dement J Alzheimers Assoc 2011;7:270-9.

doi:10.1016/j.jalz.2011.03.008.

[7] Dubois B, Feldman HH, Jacova C, Hampel H, Molinuevo JL, Blennow K, et al. Advancing research diagnostic criteria for Alzheimer's disease: the IWG-2 criteria. Lancet Neurol 2014;13:614-29. doi:10.1016/S1474-4422(14)70090-0.

[8] Blennow K, Hampel H, Weiner M, Zetterberg H. Cerebrospinal fluid and plasma biomarkers in Alzheimer disease. Nat Rev Neurol 2010;6:131-44. doi:10.1038/nrneurol.2010.4.

[9] Heneka MT, Carson MJ, El Khoury J, Landreth GE, Brosseron F, Feinstein DL, et al. Neuroinflammation in Alzheimer's disease. Lancet Neurol 2015;14:388-405. doi:10.1016/S1474-4422(15)70016-5.

[10] Prakash M, Bodas M, Prakash D, Nawani N, Khetmalas M, Mandal A, et al. Diverse pathological implications of YKL-40: answers may lie in "outside-in" signaling. Cell Signal 2013;25:1567-73. doi:10.1016/j.cellsig.2013.03.016.

[11] Lee CG, Da Silva CA, Dela Cruz CS, Ahangari F, Ma B, Kang M-J, et al. Role of chitin and chitinase/chitinase-like proteins in inflammation, tissue remodeling, and injury. Annu Rev Physiol 2011;73:479-501. doi:10.1146/annurev-physiol-012110-142250.

[12] Rehli M, Niller H-H, Ammon C, Langmann S, Schwarzfischer L, Andreesen R, et al. Transcriptional regulation of CHI3L1, a marker gene for late stages of macrophage differentiation. J Biol Chem 2003;278:44058-67. doi:10.1074/jbc.M306792200.

[13] Rehli M, Krause SW, Andreesen R. Molecular characterization of the gene for human cartilage gp-39 (CHI3L1), a member of the chitinase protein family and marker for late stages of macrophage differentiation. Genomics 1997;43:221-5. doi:10.1006/geno.1997.4778.

[14] Olsson B, Lautner R, Andreasson U, Öhrfelt A, Portelius E, Bjerke M, et al. CSF and blood biomarkers for the diagnosis of Alzheimer's disease: a systematic review and meta-analysis. Lancet Neurol 2016. doi:10.1016/S1474-4422(16)00070-3.

[15] Alcolea D, Martínez-Lage P, Sánchez-Juan P, Olazarán J, Antúnez C, Izagirre A, et al. Amyloid precursor protein metabolism and inflammation markers in preclinical Alzheimer disease. Neurology 2015;85:626-33. doi:10.1212/WNL.0000000000001859.

[16] Alcolea D, Carmona-Iragui M, Suárez-Calvet M, Sánchez-Saudinós MB, Sala I, AntónAguirre S, et al. Relationship between $\beta$-Secretase, inflammation and core cerebrospinal fluid biomarkers for Alzheimer's disease. J Alzheimers Dis JAD 2014;42:157-67. doi:10.3233/JAD-140240.

[17] Antonell A, Mansilla A, Rami L, Lladó A, Iranzo A, Olives J, et al. Cerebrospinal fluid level of YKL-40 protein in preclinical and prodromal Alzheimer's disease. J Alzheimers Dis JAD 2014;42:901-8. doi:10.3233/JAD-140624.

[18] Craig-Schapiro R, Perrin RJ, Roe CM, Xiong C, Carter D, Cairns NJ, et al. YKL-40: a novel prognostic fluid biomarker for preclinical Alzheimer's disease. Biol Psychiatry 2010;68:90312. doi:10.1016/j.biopsych.2010.08.025.

[19] Gispert JD, Monté GC, Falcon C, Tucholka A, Rojas S, Sánchez-Valle R, et al. CSF YKL-40 and pTau181 are related to different cerebral morphometric patterns in early AD. Neurobiol Aging 2016;38:47-55. doi:10.1016/j.neurobiolaging.2015.10.022.

[20] Janelidze S, Hertze J, Zetterberg H, Landqvist Waldö M, Santillo A, Blennow K, et al. Cerebrospinal fluid neurogranin and YKL-40 as biomarkers of Alzheimer's disease. Ann Clin Transl Neurol 2016;3:12-20. doi:10.1002/acn3.266.

[21] Kester MI, Teunissen CE, Sutphen C, Herries EM, Ladenson JH, Xiong C, et al. Cerebrospinal fluid VILIP-1 and YKL-40, candidate biomarkers to diagnose, predict and monitor Alzheimer's disease in a memory clinic cohort. Alzheimers Res Ther 2015;7:59. doi:10.1186/s13195-015-0142-1.

[22] Mattsson N, Tabatabaei S, Johansson P, Hansson O, Andreasson U, Månsson J-E, et al. Cerebrospinal fluid microglial markers in Alzheimer's disease: elevated chitotriosidase 
activity but lack of diagnostic utility. Neuromolecular Med 2011;13:151-9. doi:10.1007/s12017-011-8147-9.

[23] Melah KE, Lu SY-F, Hoscheidt SM, Alexander AL, Adluru N, Destiche DJ, et al. Cerebrospinal Fluid Markers of Alzheimer's Disease Pathology and Microglial Activation are Associated with Altered White Matter Microstructure in Asymptomatic Adults at Risk for Alzheimer's Disease. J Alzheimers Dis JAD 2016;50:873-86. doi:10.3233/JAD-150897.

[24] Olsson B, Hertze J, Lautner R, Zetterberg H, Nägga K, Höglund K, et al. Microglial markers are elevated in the prodromal phase of Alzheimer's disease and vascular dementia. $\mathrm{J}$ Alzheimers Dis JAD 2013;33:45-53. doi:10.3233/JAD-2012-120787.

[25] Perrin RJ, Craig-Schapiro R, Malone JP, Shah AR, Gilmore P, Davis AE, et al. Identification and validation of novel cerebrospinal fluid biomarkers for staging early Alzheimer's disease. PloS One 2011;6:e16032. doi:10.1371/journal.pone.0016032.

[26] Rosén C, Andersson C-H, Andreasson U, Molinuevo JL, Bjerke M, Rami L, et al. Increased Levels of Chitotriosidase and YKL-40 in Cerebrospinal Fluid from Patients with Alzheimer's Disease. Dement Geriatr Cogn Disord Extra 2014;4:297-304. doi:10.1159/000362164.

[27] Sutphen CL, Jasielec MS, Shah AR, Macy EM, Xiong C, Vlassenko AG, et al. Longitudinal Cerebrospinal Fluid Biomarker Changes in Preclinical Alzheimer Disease During Middle Age. JAMA Neurol 2015;72:1029-42. doi:10.1001/jamaneurol.2015.1285.

[28] Wennström M, Surova Y, Hall S, Nilsson C, Minthon L, Hansson O, et al. The Inflammatory Marker YKL-40 Is Elevated in Cerebrospinal Fluid from Patients with Alzheimer's but Not Parkinson's Disease or Dementia with Lewy Bodies. PloS One 2015;10:e0135458. doi:10.1371/journal.pone.0135458.

[29] Sperling RA, Aisen PS, Beckett LA, Bennett DA, Craft S, Fagan AM, et al. Toward defining the preclinical stages of Alzheimer's disease: recommendations from the National Institute on Aging-Alzheimer's Association workgroups on diagnostic guidelines for Alzheimer's disease. Alzheimers Dement J Alzheimers Assoc 2011;7:280-92. doi:10.1016/j.jalz.2011.03.003.

[30] McKhann G, Drachman D, Folstein M, Katzman R, Price D, Stadlan EM. Clinical diagnosis of Alzheimer's disease: report of the NINCDS-ADRDA Work Group under the auspices of Department of Health and Human Services Task Force on Alzheimer's Disease. Neurology 1984;34:939-44.

[31] Neary D, Snowden JS, Gustafson L, Passant U, Stuss D, Black S, et al. Frontotemporal lobar degeneration: a consensus on clinical diagnostic criteria. Neurology 1998;51:1546-54.

[32] McKhann GM, Knopman DS, Chertkow H, Hyman BT, Jack CR, Kawas CH, et al. The diagnosis of dementia due to Alzheimer's disease: recommendations from the National Institute on Aging-Alzheimer's Association workgroups on diagnostic guidelines for Alzheimer's disease. Alzheimers Dement J Alzheimers Assoc 2011;7:263-9. doi:10.1016/j.jalz.2011.03.005.

[33] Dubois B, Feldman HH, Jacova C, Cummings JL, Dekosky ST, Barberger-Gateau P, et al. Revising the definition of Alzheimer's disease: a new lexicon. Lancet Neurol 2010;9:1118-27. doi:10.1016/S1474-4422(10)70223-4.

[34] Blennow K, Wallin A, Agren H, Spenger C, Siegfried J, Vanmechelen E. Tau protein in cerebrospinal fluid: a biochemical marker for axonal degeneration in Alzheimer disease? Mol Chem Neuropathol Spons Int Soc Neurochem World Fed Neurol Res Groups Neurochem Cerebrospinal Fluid 1995;26:231-45. doi:10.1007/BF02815140.

[35] Vanmechelen E, Vanderstichele H, Davidsson P, Van Kerschaver E, Van Der Perre B, Sjögren M, et al. Quantification of tau phosphorylated at threonine 181 in human cerebrospinal fluid: a sandwich ELISA with a synthetic phosphopeptide for standardization. Neurosci Lett 2000;285:49-52.

[36] Vanderstichele H, Van Kerschaver E, Hesse C, Davidsson P, Buyse MA, Andreasen N, et al. Standardization of measurement of beta-amyloid(1-42) in cerebrospinal fluid and plasma. Amyloid Int J Exp Clin Investig Off J Int Soc Amyloidosis 2000;7:245-58. 
[37] Robin X, Turck N, Hainard A, Tiberti N, Lisacek F, Sanchez J-C, et al. pROC: an open-source package for R and $\mathrm{S}+$ to analyze and compare ROC curves. BMC Bioinformatics 2011;12:77. doi:10.1186/1471-2105-12-77.

[38] Xia J, Broadhurst DI, Wilson M, Wishart DS. Translational biomarker discovery in clinical metabolomics: an introductory tutorial. Metabolomics Off J Metabolomic Soc 2013;9:280-99. doi:10.1007/s11306-012-0482-9.

[39] Nonparametric Econometrics: The np Package | Hayfield | Journal of Statistical Software n.d. https://www.jstatsoft.org/article/view/v027i05 (accessed May 26, 2016).

[40] Pohlert T. The Pairwise Multiple Comparison of Mean Ranks Package (PMCMR). 2014. Available at: https://cran.r-project.org/web/packages/PMCMR/vignettes/PMCMR.pdf.

[41] Cairns NJ, Bigio EH, Mackenzie IRA, Neumann M, Lee VM-Y, Hatanpaa KJ, et al. Neuropathologic diagnostic and nosologic criteria for frontotemporal lobar degeneration: consensus of the Consortium for Frontotemporal Lobar Degeneration. Acta Neuropathol (Berl) 2007;114:5-22. doi:10.1007/s00401-007-0237-2.

[42] Glass CK, Saijo K, Winner B, Marchetto MC, Gage FH. Mechanisms underlying inflammation in neurodegeneration. Cell 2010;140:918-34. doi:10.1016/j.cell.2010.02.016.

[43] Hoozemans JJM, Veerhuis R, Rozemuller AJM, Eikelenboom P. Non-steroidal antiinflammatory drugs and cyclooxygenase in Alzheimer's disease. Curr Drug Targets 2003;4:461-8.

[44] Pasinetti GM. From epidemiology to therapeutic trials with anti-inflammatory drugs in Alzheimer's disease: the role of NSAIDs and cyclooxygenase in beta-amyloidosis and clinical dementia. J Alzheimers Dis JAD 2002;4:435-45.

[45] ADAPT Research Group, Martin BK, Szekely C, Brandt J, Piantadosi S, Breitner JCS, et al. Cognitive function over time in the Alzheimer's Disease Anti-inflammatory Prevention Trial (ADAPT): results of a randomized, controlled trial of naproxen and celecoxib. Arch Neurol 2008;65:896-905. doi:10.1001/archneur.2008.65.7.nct70006.

[46] Breitner JC, Baker LD, Montine TJ, Meinert CL, Lyketsos CG, Ashe KH, et al. Extended results of the Alzheimer's disease anti-inflammatory prevention trial. Alzheimers Dement J Alzheimers Assoc 2011;7:402-11. doi:10.1016/j.jalz.2010.12.014.

[47] Lista S, Garaci FG, Toschi N, Hampel H. Imaging epigenetics in Alzheimer's disease. Curr Pharm Des 2013;19:6393-415.

[48] Mascalchi M, Ginestroni A, Toschi N, Poggesi A, Cecchi P, Salvadori E, et al. The burden of microstructural damage modulates cortical activation in elderly subjects with MCI and leukoaraiosis. A DTI and fMRI study. Hum Brain Mapp 2014;35:819-30. doi:10.1002/hbm.22216.

[49] Akiyama H, Barger S, Barnum S, Bradt B, Bauer J, Cole GM, et al. Inflammation and Alzheimer's disease. Neurobiol Aging 2000;21:383-421.

\section{ACKNOWLEDGEMENTS}

Harald Hampel is supported by the AXA Research Fund, the Fondation Universite Pierre et Marie Curie and the Fondation pour la Recherche sur Alzheimer, Paris, France. Ce travail a bénéficié d'une aide de l'Etat « Investissements d'avenir » ANR-10-IAIHU-06 (HH). The research leading to these results has received funding from the program "Investissements d'avenir" ANR-10-IAIHU-06 (Agence Nationale de la Recherche-10-IA Agence Institut Hospitalo-Universitaire-6) (HH).

Kaj Blennow is supported by the Swedish Research Council, the Torsten Söderberg Foundation, the Swedish Brain Foundation and the Swedish Alzheimer Foundation. Henrik Zettenberg is supported by the Knut and Alice Wallenberg Foundation, the Swedish Research Council, the European Research Council, the Swedish Brain Foundation and Frimurarestiftelsen. 


\section{Disclosure statement:}

Filippo Baldacci, Nicola Toschi, Enrica Cavedo, Francesco Garaci, Roberto Floris, Ingo Kilimann, Stefan Teipel, Antonio Melo dos Santos, Foudil Lamari have nothing to declare.

Simone Lista has received lecture honoraria from Roche.

Kaj Blennow and Henrik Zetterberg are co-founders of Brain Biomarker Solutions in Gothenburg $\mathrm{AB}$, a GU Venture-based platform company at the University of Gothenburg.

Kaj Blennow has served as a consultant or at advisory boards for IBL International, Roche Diagnostics, Eli Lilly, Fujirebio Europe, and Novartis.

Ubaldo Bonuccelli has received fees for consultation from GSK and Eisai and for speeches from Novartis, GSK and Lundbeck.

Stéphane Epelbaum reports no conflict of interest with the present manuscript. He received lecture honoraria from Roche and participated on scientific advisory boards of GE Healthcare and Eli Lilly. Bruno Dubois has served as a consultant or at advisory boards from Eli Lilly, Cytox Ltd and Boehringer-Ingelheim.

Harald Hampel reports no conflict of interest with the present manuscript. He serves as Senior Associate Editor for the journal Alzheimer's \& Dementia; he has been a scientific consultant and/or speaker and/or attended scientific advisory boards of Axovant, Anavex, Eli Lilly and company, GE Healthcare, Cytox Ltd, Jung Diagnostics GmbH, Roche, Biogen Idec, Takeda-Zinfandel, Oryzon Genomics; and receives research support from the Association for Alzheimer Research (Paris), Pierre and Marie Curie University (Paris), Pfizer \& Avid (paid to institution); and has patent applications, but receives no royalties.

\section{CAPTIONS TO THE FIGURES}

Figure 1. Stratification of the cohort according to the 2 levels of classification. Level I of categorization followed only a clinical diagnostic approach. It included HC, MCI, ADD, and FTD participants.

Level II of categorization followed a simplified version of the biomarker-based descriptive classification model recently proposed by Jack and colleagues: the "A/T/N" system [4]. It included: Group 1, HC; Group 2, [A-/T-/N-]; Group 3, [A-/T $\pm / \mathrm{N}+$ or A-/T+/N \pm$]$; Group 4, [A+/T-/N-]: Group 5; $[\mathrm{A}+/ \mathrm{T} \pm / \mathrm{N}+$ or $\mathrm{A}+/ \mathrm{T}+/ \mathrm{N} \pm]$; Group 6, FTD.

The figure shows how the participants have been stratified from Level 1 to Level II, according to the $\mathrm{A} / \mathrm{T} / \mathrm{N}$ classification scheme.

Abbreviations: $\mathrm{ADD}=$ Alzheimer's disease dementia; $\mathrm{FTD}=$ frontotemporal dementia; $\mathrm{HC}=$ cognitively healthy controls; $\mathrm{MCI}=$ mild cognitive impairment.

$\mathrm{A}=$ amyloid biomarker $\left(\mathrm{A} \beta_{1-42}\right) ; \mathrm{T}=$ tau pathology biomarker $(\mathrm{p}$-tau); $\mathrm{N}=$ biomarker of neurodegeneration or neuronal injury ( $\mathrm{t}$-tau).

Figure 2. Boxplots showing CSF YKL-40 concentrations (adjusted for sex, age and site) in AD patients, MCI patients, FTD patients, and cognitively HCs (Level I) (A). Boxplots showing CSF YKL-40 concentrations (adjusted for sex, age and site) in all 6 groups (Level II) (B). The lower, upper, and middle lines correspond to the 25 th centile, 75 th centile, and median, respectively. The whiskers extend to the minimum and maximum YKL-40 data points. Dark circles represent outliers. Group-wise comparisons of YKL-40 values were conducted through nonparametric KW tests followed by pairwise comparison (Conover's-test for multiple comparisons).

Abbreviations: $\mathrm{AD}=$ Alzheimer's disease; $\mathrm{CSF}=$ cerebrospinal fluid; $\mathrm{FTD}=$ frontotemporal dementia; $\mathrm{HC}=$ healthy controls; $\mathrm{KW}=$ Kruskal-Wallis; $\mathrm{MCI}=$ mild cognitive impairment. 
$\mathrm{A}=$ amyloid biomarker $\left(\mathrm{A} \beta_{1-42}\right) ; \mathrm{T}=$ tau pathology biomarker ( $\mathrm{p}$-tau); $\mathrm{N}=$ biomarker of neurodegeneration or neuronal injury (t-tau).

Figure 3. The AUROC curves result from fitting a logistic regression model within a LOO-CV scheme to YKL-40 data adjusted for age, sex, and site in the following binary classification problems: $\mathrm{HC}$ versus $\mathrm{AD}$ (A, left) and $\mathrm{AD}$ versus $\mathrm{FTD}(\mathrm{B}$, right)

Abbreviations: $\mathrm{AD}=$ Alzheimer's disease; $\mathrm{AUC}=$ Area under the $\mathrm{ROC}$ curve. $\mathrm{C} . \mathrm{I}=$ confidence intervals (computed using a bootstrap procedure with 10000 bootstraps); $\mathrm{CSF}=$ cerebrospinal fluid; $\mathrm{FTD}=$ frontotemporal dementia; $\mathrm{HC}=$ healthy controls; $\mathrm{LOO}-\mathrm{CV}=$ leave-one out cross validation; $\mathrm{MCI}=$ mild cognitive impairment.

$\mathrm{A}=$ amyloid biomarker $\left(\mathrm{A} \beta_{1-42}\right) ; \mathrm{T}=$ tau pathology biomarker ( $\mathrm{p}$-tau); $\mathrm{N}=$ biomarker of neurodegeneration or neuronal injury (t-tau).

Figure 4. The AUROC curves result from fitting a logistic regression model within a LOO-CV scheme to neurogranin data adjusted for age, sex, and site in the following binary classification problems: Group 1 versus Group 3 (A, top left), Group 1 versus Group 4 (B, top right), Group 1 versus Group 5 (C, bottom left), Group 5 versus Group 6 (D, bottom right).

Abbreviations: $\mathrm{AD}=$ Alzheimer's disease; $\mathrm{AUC}=$ Area under the $\mathrm{ROC}$ curve. C.I.= confidence intervals (computed using a bootstrap procedure with 10000 bootstraps); $\mathrm{CSF}=$ cerebrospinal fluid; LOO-CV $=$ leave-one out cross validation.

$\mathrm{A}=$ amyloid biomarker $\left(\mathrm{A} \beta_{1-42}\right) ; \mathrm{T}=$ tau pathology biomarker $(\mathrm{p}$-tau); $\mathrm{N}=$ biomarker of neurodegeneration or neuronal injury (t-tau). 


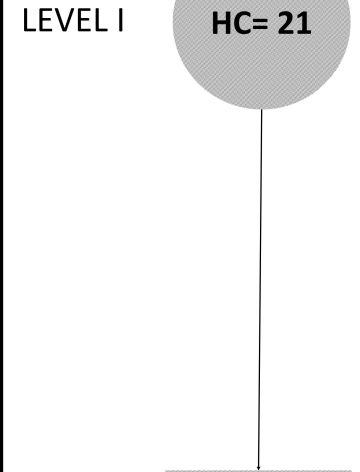

LEVEL II

Group 1
$\mathrm{MCl}=41$

$A D D=35$

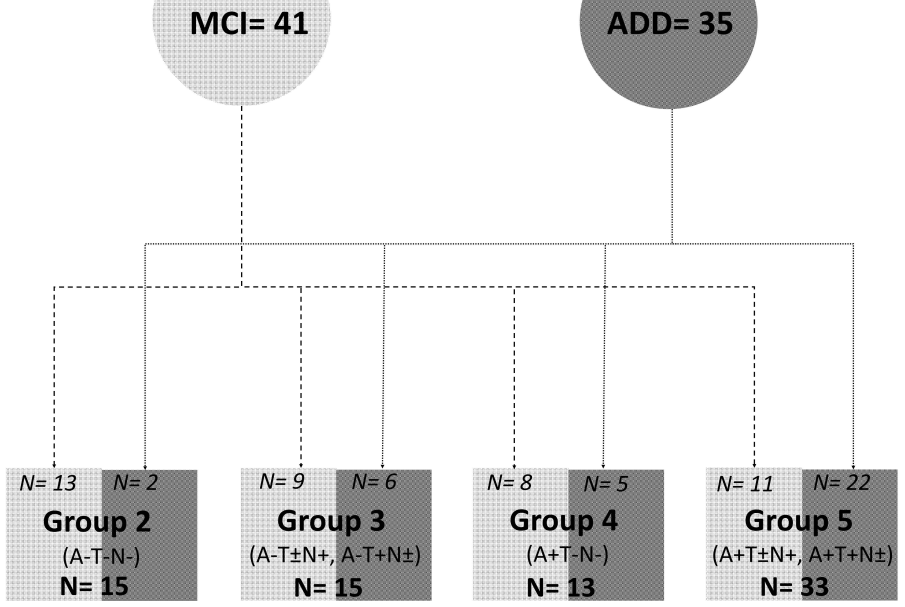

FTD $=9$

(HC)

$\mathbf{N}=\mathbf{2 1}$
$\mathbf{N}=15$
$\mathbf{N}=13$

$\mathrm{N}=\mathbf{3 3}$

Group 6

(FTD)

$\mathrm{N}=\mathbf{9}$ 

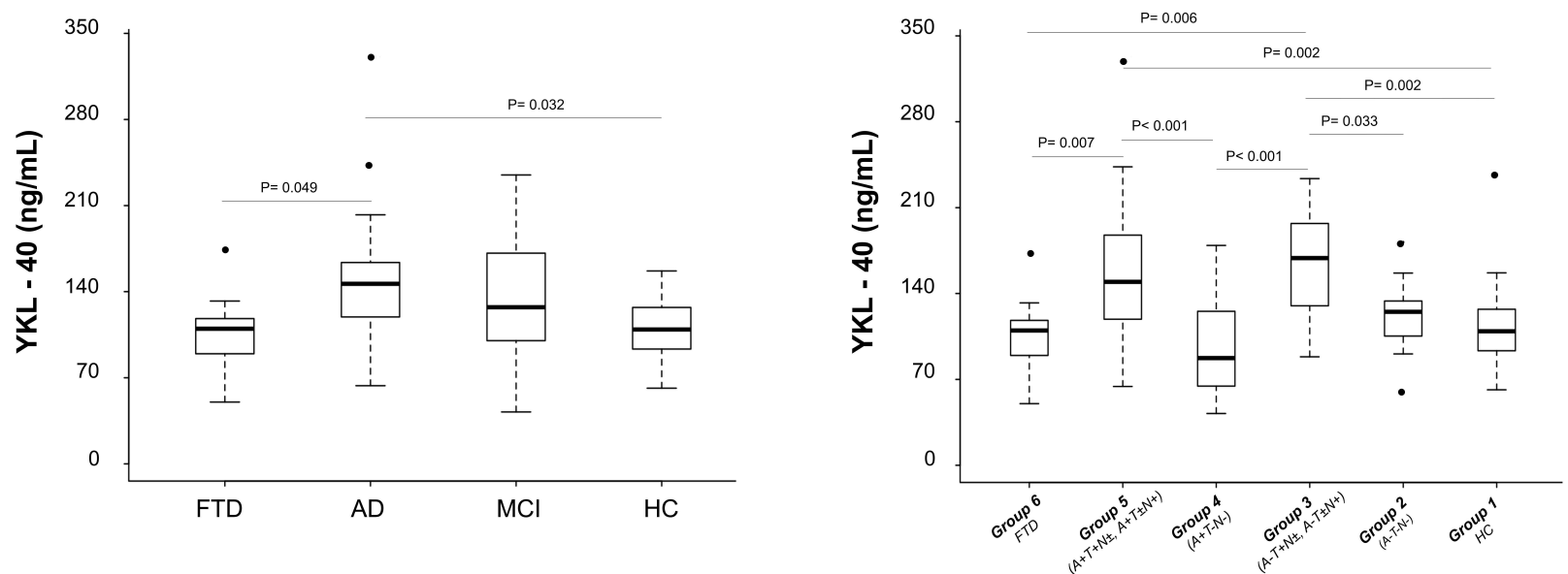


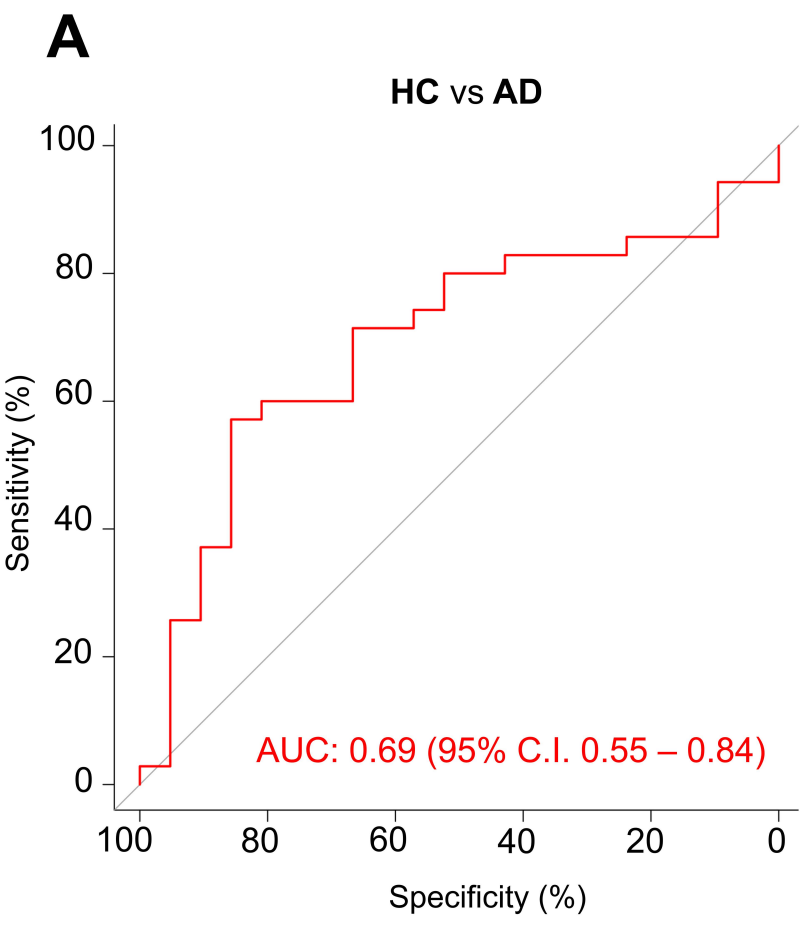

\section{B}

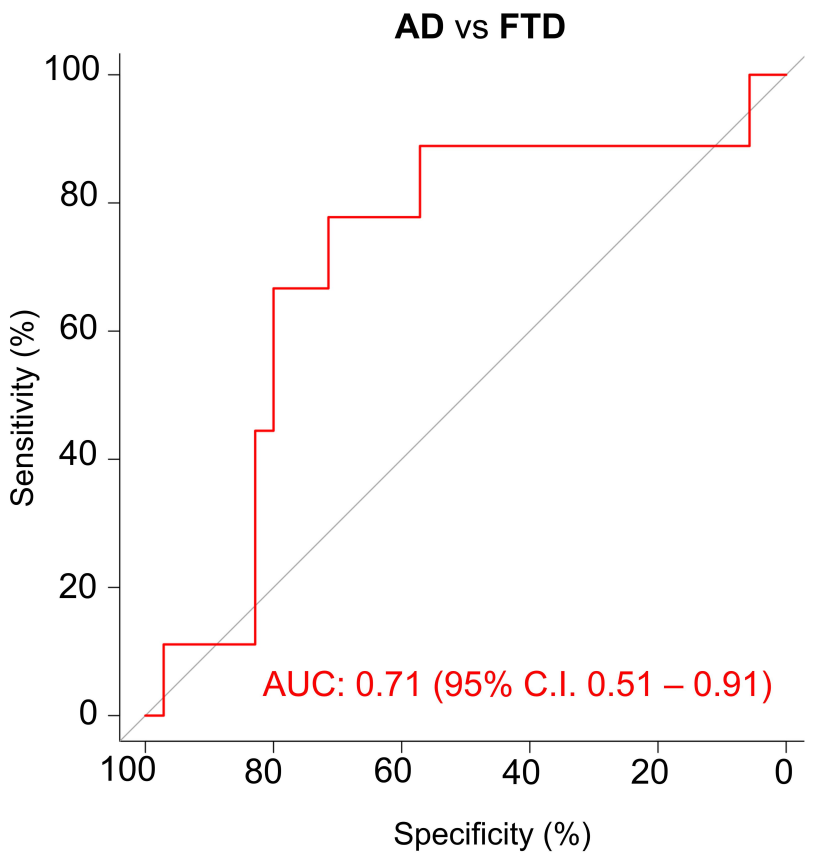


A

Group 1 vs Group 3

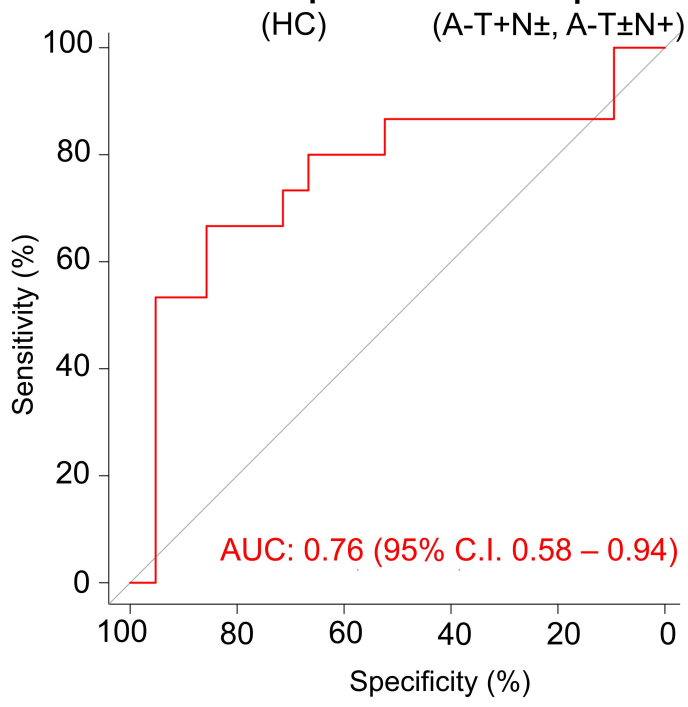

B
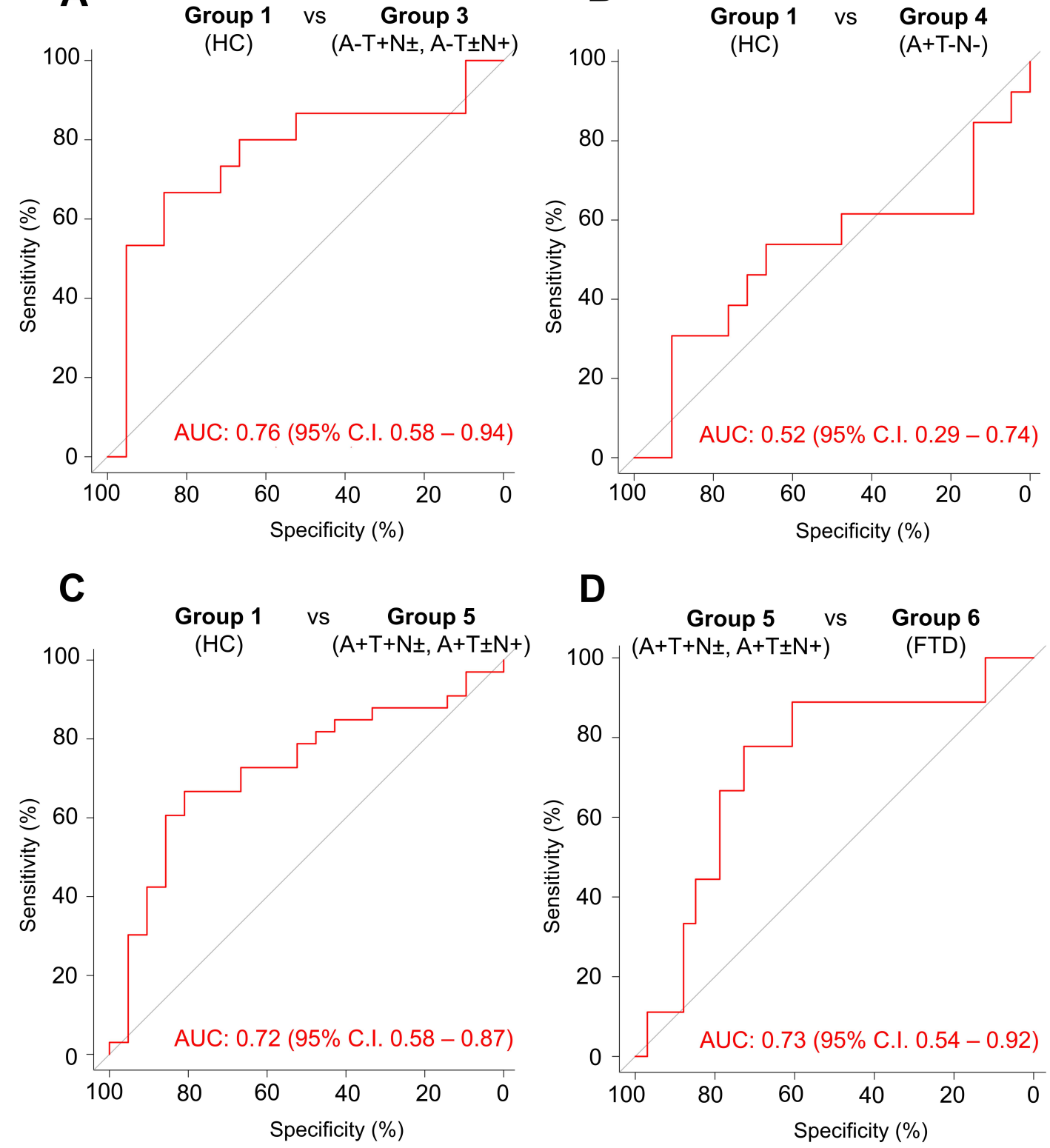
Table 1. Summary of the demographic, clinical, and biomarker data of the population (Level I).

\begin{tabular}{|c|c|c|c|c|}
\hline & \multicolumn{4}{|c|}{ LEVEL I } \\
\hline & $\mathrm{HC}$ & MCI & $\mathrm{AD}$ & FTD \\
\hline Sex, n (F/M) & $21(13 / 8)$ & $41(14 / 27)$ & $35(24 / 11)$ & $9(5 / 4)$ \\
\hline Age at LP (y) & $64(59-59)$ & $72(65-75) \#$ & $73(68-76) \#$ & $73(70-74)^{*}$ \\
\hline MMSE at LP $(/ 30)$ & $30(29-30)$ & $26(24-28)$ & $23(19-26)^{*} \dagger$ & $23(19-26)$ \\
\hline CSF YKL-40 (ng/mL) & $98(90-110)$ & $128(98-184)$ & $146(119-177) * \S$ & $114(98-120)$ \\
\hline $\operatorname{CSF} A \beta_{1-42}(\mathrm{pg} / \mathrm{mL})$ & $910(785-996)$ & $540(411-911)^{*}$ & $424(374-503) \S \# \rrbracket$ & $652(530-823)$ \\
\hline CSF t-tau (pg/mL) & $201(127-243)$ & $261(189-452)$ & $496(360-764) \dagger \S \#$ & $208(161-340)$ \\
\hline CSF p-tau (pg/mL) & $44(35-48)$ & $60(44-80)$ & $83(64-126) * \dagger \S$ & $31(27-53)$ \\
\hline
\end{tabular}

Abbreviations: $\mathrm{A} \beta_{1-42}, 42$-amino acid-long amyloid beta peptide; AD, Alzheimer's disease; CSF, cerebrospinal fluid; HC, cognitively healthy controls; F, female; FTD, frontotemporal dementia; LP, lumbar puncture; M, male; MCI, mild cognitive impairment; MMSE, mini-mental state examination; p-tau, hyperphosphorylated tau; t-tau, total tau.

NOTE. All data are median values with $25^{\text {th }}$ and $75^{\text {th }}$ quartiles, except for $\mathrm{n}$.

For statistical comparisons, the above MMSE, YKL-40, A $\beta 1-42$, t-tau, $p$-tau comparisons were adjusted for age, sex, and site.

$* P<0.05$ vs $\mathrm{HC} ; \dagger P<0.05$ vs $\mathrm{MCI} ; \ddagger P<0.05$ vs $\mathrm{AD} ; \S P<0.05$ vs FTD.

$\# P<0.001$ vs $\mathrm{HC} ; \Phi P<0.001$ vs $\mathrm{MCI}$ 
Table 2. Summary of the demographic, clinical, and biomarker data of the population (Level II).

\begin{tabular}{|c|c|c|c|c|c|c|}
\hline & \multicolumn{6}{|c|}{ LEVEL II } \\
\hline & Group 1 & Group 2 & Group 3 & Group 4 & Group 5 & Group 6 \\
\hline & $\mathrm{HC}$ & [A-T-N-] & {$[\mathrm{A}-\mathrm{T}+\mathrm{N} \pm, \mathrm{A}-\mathrm{T} \pm \mathrm{N}+]$} & {$[\mathrm{A}+\mathrm{T}-\mathrm{N}-]$} & {$[\mathrm{A}+\mathrm{T}+\mathrm{N} \pm, \mathrm{A}+\mathrm{T} \pm \mathrm{N}+]$} & FTD \\
\hline Sex, n (F/M) & $13 / 8$ & $4 / 11$ & $8 / 7$ & $7 / 6$ & $19 / 14$ & $5 / 4$ \\
\hline Age at LP & $64(59-69)$ & $65(56-71)$ & $75(69-77) \dagger^{* * *}$ & $72(68-75) * \dagger$ & $74(69-76) \dagger^{* *}$ & $73(70-74)^{*} \dagger$ \\
\hline MMSE & $30(29-30)$ & $28(26-29)$ & $25(20-27)$ & $25(23-27)$ & $24(19-26)$ & $23(19-26)$ \\
\hline CSF YKL-40 (ng/mL) & $98(90-110)$ & $109(80-137)$ & $182(122-215)^{* \dagger}$ & $87(74-135)+4$ & $155(128-196) * \llbracket \S \S$ & $114(98-120) \$$ \\
\hline CSF A $\beta 1-42(\mathrm{pg} / \mathrm{mL})$ & $910(785-996)$ & $872(803-1243)$ & $886(586-1025)$ & $377(293-432) * *+\dagger+99$ & $406(366-448)^{* *+\dagger \dagger+999}$ & $652(530-823) \dagger$ \\
\hline CSF t-tau (pg/mL) & $201(127-243)$ & $170(141-215)$ & $461(390-537)^{* * \dagger \dagger \S \S 9 \uparrow \mid ~}$ & $195(168-240)$ & 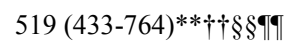 & $208(161-340)$ \\
\hline CSF p-tau (pg/mL) & $44(35-48)$ & $44(43-52)$ & 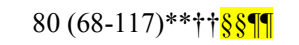 & $44(30-51)$ & 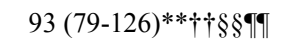 & $31(27-53)$ \\
\hline
\end{tabular}

Abbreviations: $\mathrm{A} \beta_{1-42}, 42$-amino acid-long amyloid beta peptide; AD, Alzheimer's disease; CSF, cerebrospinal fluid; HCs, cognitively healthy controls; F, female; FTD, frontotemporal dementia; LP, lumbar puncture; M, male; MCI, mild cognitive impairment; MMSE, mini-mental state examination; p-tau, hyperphosphorylated tau; t-tau, total tau.

NOTE. All data are median values with $25^{\text {th }}$ and $75^{\text {th }}$ quartiles, except for $n$.

For statistical comparisons, the above MMSE, YKL-40, A $\beta 1-42$, t-tau, p-tau comparisons were adjusted for age, sex, and site.

$* P<0.05$ vs HCs; $\uparrow P<0.05$ vs Group $2 ; \ddagger P<0.05$ vs Group $3 ; \S P<0.05$ vs Group $4 ; \# P<0.05$ vs Group 5 ; $\uparrow P<0.05$ vs Group 6 .

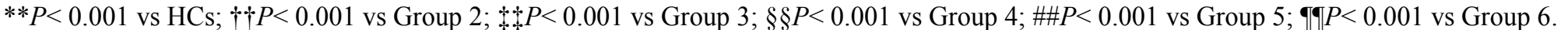

